\title{
Performance of adjuvant treatment correlates with survival in reoperated glioblastomas
}

\author{
Uso de tratamento adjuvante é relacionado ao aumento da sobrevida em pacientes com \\ glioblastoma submetidos à reoperação
}

Willey Gonçalves Zanovello', Suzana M. F. Malheiros', João Norberto Stavale², Orestes P. Lanzoni', Miguel M.

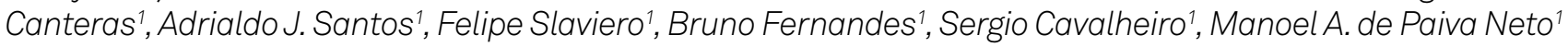

\begin{abstract}
Objective: To analyze cases of recurrent glioblastoma subjected to reoperation at a Brazilian public healthcare service. Methods: A total of 39 patients subjected to reoperation for recurrent glioblastoma at the Department of Neurosurgery, São Paulo Hospital, Federal University of São Paulo, from January 2000 to December 2013 were retrospectively analyzed. Results: The median overall survival was 20 months (95\% confidence interval $-\mathrm{Cl}=14.9-25.2)$, and the median survival after reoperation was 9.1 months (95\%Cl: 2.8-15.4). The performance of adjuvant treatment after the first operation was the single factor associated with overall survival on multivariate analysis (relative risk $-\mathrm{RR}=0.3 ; 95 \% \mathrm{Cl}=0.2-0.7) ; \mathrm{p}=0.005$ ). Conclusion: The length of survival of patients subjected to reoperation for glioblastoma at a Brazilian public healthcare service was similar to the length reported in the literature. Reoperation should be considered as a therapeutic option for selected patients.
\end{abstract}

Keywords: glioblastoma; reoperation; general surgery; survival.

RESUMO

Objetivo: Analisar o papel da reoperação em pacientes com glioblastoma recidivado em um serviço público no Brasil. Métodos: Foram analisados retrospectivamente 39 pacientes submetidos à reoperação por recorrência de glioblastoma no Departamento de Neurocirurgia da Universidade Federal de São Paulo, no período de janeiro de 2000 até dezembro de 2013. Resultados: A sobrevida global mediana foi de 20 meses (IC 95\% = 14.9-25.2), e a sobrevida mediana após a reoperação foi de 9.1 meses (IC 95\% = 2.8-15.4). A realização de tratamento adjuvante após a primeira cirurgia foi o único fator associado com a sobrevida global numa análise multivariada $(R R=0.3 ; \mathrm{IC} 95 \%=0.2-0.7$; $p=0.005)$. Conclusão: A sobrevida dos pacientes submetidos à reoperação em um serviço público no Brasil é semelhante à reportada pela literatura. A reoperação deve ser considerada como uma opção terapêutica em pacientes selecionados.

Palavras-chave: glioblastoma; reoperação; cirurgia geral; sobrevivência.

Glioblastoma (GBM) is the most common primary tumor affecting the central nervous system and represents more than $50 \%$ of glial tumors ${ }^{1}$. In spite of the advances in microsurgery to accomplish optimized resections (extensive, without worsening of the neurologic function), followed by standard treatment with concomitant radiotherapy (RT) and chemotherapy (CT) and maintenance therapy with temozolomide (TMZ) ${ }^{2}$, the patients' survival remains rather limited, with small survival gains obtained in recent years ${ }^{3,4,5}$.

The main factors associated with patient survival are age and functional status before surgery ${ }^{6,7}$; the extent of resection ${ }^{7.8}$, adjuvant treatment ${ }^{7,9}$ and methylation of the O6-methylguanine-DNA methyltransferase (MGMT) promoter ${ }^{10}$, which also seem to be associated with increased survival. The role of surgical treatment for recurrence or regrowth of GBM has not yet been fully established. While some authors recommend reoperation ${ }^{11,12,13}$, others did not find increased survival with this strategy ${ }^{14,15}$.

Despite the large number of studies published in recent years demonstrating the benefits of reoperation in patients with recurrent GBM, we were not able to locate any similar study conducted in Brazil. Thus, we assessed a group of patients with recurrent GBM subjected to reoperation at a Brazilian public healthcare service aiming at describing the clinical characteristics of patients and identifying the ones who might benefit from this treatment modality.

'Universidade Federal de São Paulo, Departamento de Neurocirurgia, São Paulo SP, Brasil;

¿Universidade Federal de São Paulo, Departamento de Patologia, São Paulo SP, Brasil.

Correspondence: Manoel A. Paiva Neto; Universidade Federal de São Paulo, Departamento de Neurocirurgia; Rua Leandro Dupret, 847 ; $04025-013$ São Paulo SP, Brasil; E-mail: mapnpaiva@ig.com.br

Conflict of interest: There is no conflict of interest to declare.

Received 04 February 2016; Received in final form 29 May 2016; Accepted 09 August 2016. 


\section{METHODS}

We performed a retrospective and descriptive analysis of patients followed up at the Neurosurgery Section, who were diagnosed with GBM (World Health Organization grade IV) from January 2000 to December 2013 and subjected to reoperation due to tumor recurrence or regrowth. The patients were followed up until February 2015.

The data were collected from the patients' medical records and the database of the Neuro-oncology unit, Discipline of Neurosurgery, UNIFESP, having been treated by the same neuro-oncologist in a linear manner (SMFM).

The study population included patients older than 18 years of age, subjected to reoperation due to recurrence or progression of tumors diagnosed as GBM upon histopathological examination at the first operation. Patients subjected to only one biopsy in one of the surgeries, those who underwent reoperation due to complications, and cases with missing data were excluded from the present study.

The indication for reoperation was established in periodic multidisciplinary meetings that included neurosurgeons, neuro-oncologists, neurologists and neuroradiologists. Patients with Karnofsky Performance Status (KPS) scores equal to or higher than 70 and tumors likely to be entirely resected and located in non-eloquent brain areas were considered as candidates for reoperation.

The variables analyzed were age, gender, initial symptom, initial KPS score, duration of symptoms, tumor localization, tumor laterality, extent of resection in both surgical procedures, localization of the recurrent tumor, time elapsed between the operations, adjuvant treatment after primary surgery and reoperation, delay in the onset $\mathrm{RT}$, time of relapse relative to reoperation, overall survival (OS), survival after reoperation (SARp) and survival after relapse (SAR).

The extent of resection was established based on computed tomography and/or magnetic resonance imaging (MRI) of the brain, both with contrast and performed within the first 72 hours after surgery. Resection was considered to be total (TR) when non-linear contrast enhancement was not found in the control test and was considered partial (PR) when enhancement was found (presence of residual lesion).

Recurrence was defined as the appearance of a new lesion in the control test of any patient subjected to TR, and regrowth as more than a $25 \%$ increase in residual lesions after the first operation. Spectroscopy and perfusion MRI were used in the differential diagnosis of pseudo-progression as per our service routine. Recurrence was considered to be local when it appeared in the same brain lobe as the primary tumor and as distant when it appeared in any other lobe or the contralateral brain hemisphere. Adjuvant treatment was defined as performance of RT and/or CT. Radiotherapy delay was defined as any interval longer than six weeks between the first operation and the onset of RT.
Overall survival was defined as the time elapsed from the date of the first operation to death and SARp as the time elapsed from the date of reoperation to death.

The study was approved by the research ethics committee of UNIFESP, ruling no. 1,093,864.

\section{Statistical analysis}

The categorical variables are expressed as percentages and the continuous ones as medians (ranges), as befitting. The event cumulative curves were estimated using the Kaplan-Meier method and were compared via the log-rank test. The patients lost to follow-up were censored at their last follow-up visit, and patients who completed the study were censored in February 2015.

Univariate and multivariate Cox regression was performed as needed. All variables with $\mathrm{p}<0.1$ on multivariate analysis or considered as having confirmed clinical relevance were included in the multivariate model. Multicollinearity problems were solved before including the variables in the model. The possible interactions between the variables that were kept in the model were tested. The assumption of risk proportionality was tested using the Schoenfield residuals. The significance level was set as $\mathrm{p}<0.05$.

\section{Characteristics of the patients}

A total of 167 patients were subjected to the same surgical procedure. The data corresponding to 48 patients subjected to reoperation for tumor recurrence or regrowth were initially included. However, nine patients had to be excluded because biopsy had only been performed in the first operation in six cases and the second biopsy in the other three. Thus, the sample included a total of 39 patients.

Table 1 describes the demographic and clinical characteristics of the included patients. Their median age was 49 years old (20 to 79 years old); 26 patients were male (66\%). Headache was the most common initial symptom of disease, occurring in 23 patients (59\%); followed by seizures, 11 cases (28\%); and motor deficit, behavioral changes, dizziness and vomiting, one case each (3\%). The median preoperative KPS score was 80, and the postoperative KPS score of the first surgery was 90 (assessed at the first follow-up visit). The median duration of symptoms from the date of the appearance of the first symptom to the first operation was eight weeks (ranging from one to 103 weeks).

\section{RESULTS}

Table 2 describes the extent of resection in each operation and the interval of time between them. The first operation was classified as TR in 23 cases (59\%) and as PR in 16 (41\%). The second operation was classified as TR in 21 cases (54\%) and as PR in 18 (46\%).

Recurrence was local in 34 cases (87\%), distant in three (8\%) and both local and distant in two cases (5\%). The median time elapsed between the two operations was 4.7 months ( 0.7 to 54.1 months). 
Five patients were subjected to a third operation, with three cases of TR and two of PR.

The morbidity rate corresponding to the first operation was $2.6 \%$, with no cases of perioperative death. The morbidity rate corresponding to reoperation was $20.5 \%$ (eight patients): three cases of surgical wound infection that required surgical cleansing, one of which progressed into osteomyelitis; one patient exhibited transient hemihypesthesia; and four exhibited permanent neurological aggravation, hemiplegia and aphasia in two cases, sleepiness and ataxia in one, and behavioral disorders in one.

Table 3 describes the data relative to adjuvant treatment. A total of 33 patients (83\%) recieved CT, 18 (55\%) using

Table 1. Sociodemographic and clinical characteristics of the 39 analyzed patients.

\begin{tabular}{|cc}
\hline Characteristics & Number of patients \\
\hline Gender & \\
\hline Male & $26(66 \%)$ \\
\hline Female & $13(34 \%)$ \\
\hline Median age & $49(20-79)$ \\
\hline Initial KPS score & 80 \\
\hline Median & $9(23 \%)$ \\
\hline$<70$ & $30(77 \%)$ \\
\hline$\geq 70$ & \\
\hline Initial tumor localization & $18(46 \%)$ \\
\hline Right hemisphere & $21(54 \%)$ \\
\hline Left hemisphere & $11(28 \%)$ \\
\hline Temporal & $10(26 \%)$ \\
\hline Frontal & $2(5 \%)$ \\
\hline Parietal & $1(3 \%)$ \\
\hline Occipital & $15(38 \%)$ \\
\hline Multilobar & \\
\hline Initial symptom & $23(59 \%)$ \\
\hline Headache & $11(28 \%)$ \\
\hline Seizure & $5(13 \%)$ \\
\hline Other & $34(87 \%)$ \\
\hline Recurrence & $3(8 \%)$ \\
\hline Local & $2(5 \%)$ \\
\hline Distant & \\
\hline Local + distant & \\
\hline
\end{tabular}

KPS: Karnofsky performance status.

Table 2. Extent of resection in each operation and interval of time between operations.

\begin{tabular}{lc}
\hline Operation & Number of patients \\
\hline First & \\
TR & $23(59 \%)$ \\
\hline PR & $16(41 \%)$ \\
Reoperation & $21(54 \%)$ \\
\hline TR & $18(46 \%)$ \\
PR & \\
Interval between operations & 4.7 months $(0.7$ to 54.1$)$ \\
\hline Median & $21(54 \%)$ \\
$\leq 6$ months & $18(46 \%)$ \\
\hline 6 months &
\end{tabular}

TR: total resection; PR: partial resection. carmustine (bis-chloroethylnitrosourea, BCNU), 14 (42\%) using TMZ and one (3\%) using BCNU/procarbazine, lomustine, and vincristine (PCV). It should be noted that TMZ became available in our service starting May 2009; from that moment onwards, only one out of 15 patients used $\mathrm{BCNU}$ due to social reasons, while all of the others were treated with TMZ. Among the 33 patients who used TMZ, $11(33 \%)$ received CT after reoperation only. The median time to onset of CT was 16 weeks.

A total of 35 patients (88\%) were subjected to RT, with a median dose of 60 Gy. The median time to onset of RT was eight weeks. Onset of RT was delayed beyond six weeks in 29 cases $(74 \%)$.

Recurrence occurred before the onset of or in the course of RT in 18 cases (46\%) and after the end of RT in 21 cases (54\%).

It should be noted that adjuvant treatment after reoperation was not uniform. The patients who had received standard adjuvant treatment after the first operation (RT followed by CT with BCNU until 2009 and with TMZ afterwards) were indicated for additional CT and/or RT (maintenance of TMZ for a protracted regimen, bevacizumab or re-irradiation). In turn, the patients who had not been given adjuvant therapy after the first operation were indicated for the standard regimen after reoperation.

The median survival after reoperation was 9.1 months $(95 \% \mathrm{CI}=2.8-15.4)$, and the median OS was 20 months (95\%CI $=14.9-25.2)$.

On univariate analysis, the variables associated with OS were performance of adjuvant treatment before the first operation (Figure 1) and an interval between operations longer than six months. On multivariate analysis, adjuvant treatment after the first surgery was the only independent variable associated with OS (relative risk $-\mathrm{RR}=0.3$; 95\%CI $=0.2-0.7$; $\mathrm{p}=0.005$ ) after adjustment for KPS score, age and interval of time between operations (Table 4).

On univariate analysis, the variables associated with SARp were $\mathrm{TR}$ at reoperation $(\mathrm{RR}=0.3 ; 95 \% \mathrm{CI}=0.1-0.7$;

Table 3. Characteristics of adjuvant treatment.

\begin{tabular}{|cc}
\hline Adjuvant treatment & Number of patients \\
\hline Chemotherapy & \\
\hline No & $9(15 \%)$ \\
\hline Yes & $33(85 \%)$ \\
\hline BCNU & $18(55 \%)$ \\
\hline TMZ & $14(42 \%)$ \\
\hline BCNU/PCV & $1(3 \%)$ \\
\hline Radiotherapy & \\
\hline No & $4(12 \%)$ \\
\hline Yes & $35(88 \%)$ \\
\hline Delay $(>6$ weeks) & $29(74 \%)$ \\
\hline
\end{tabular}

BCNU: bis-chloroethylnitrosourea; TMZ: temozolomide; BCNU/PCV: bischloroethylnitrosourea/ procarbazine, lomustine, and vincristine. 
$\mathrm{p}=0.005)$ and adjuvant treatment after reoperation $(\mathrm{RR}=0.4$; $95 \% \mathrm{CI}=0.2-0.8 ; \mathrm{p}=0.016)$. Multivariate analysis detected an interaction between those two variables. In the analysis stratified per extent of resection (Figure 2), relative to the group that received adjuvant treatment after reoperation, the median SARp was longer in the patients with subtotal resection at reoperation (p: 0.044). Relative to the patients with $\mathrm{TR}$, adjuvant treatment after reoperation was not associated with longer SARp $(p=0.089)$.

Delayed onset of RT was not associated with OS in the analyzed sample of patients. Separate additional analysis of the patients in which onset of RT was delayed did not show any difference in OS between the ones who had tumor relapse before/during RT (15 cases) and the ones in whom the tumor had relapsed after the end of $\mathrm{RT}$ ( 14 cases), $\mathrm{RR}=2.0$ (95\% CI = $0.8-4.8 ; \mathrm{p}=0.11$ ).

\section{DISCUSSION}

In the present study, we performed a descriptive analysis of patients subjected to reoperation for recurrent GBM. Survival may be longer in our sample (20 months) compared to the median survival of patients with GBM reported in the literature, which varied from six to 18 months ${ }^{4,16}$.

\section{Role of reoperation in overall survival}

In our study, the OS was 20 months, consistent with those found in the literature. McNamara et al. ${ }^{17}$ compared 104 patients who underwent repeated surgery with 397 who underwent primary surgery only and found that the OS

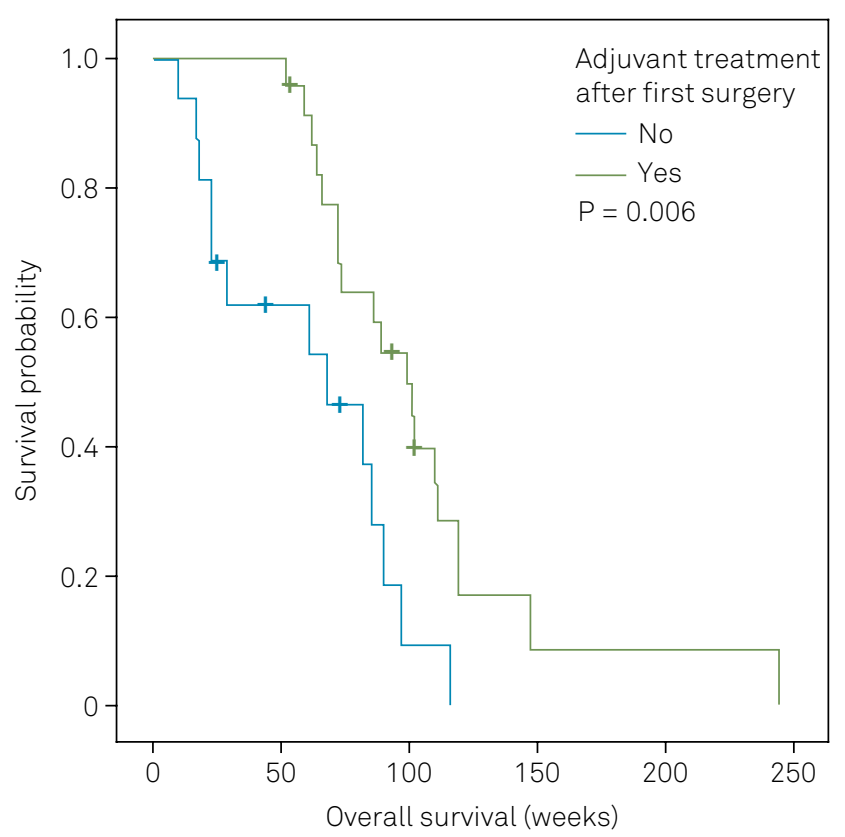

Figure 1. Kaplan-Meier curve representing the overall survival (OS) of patients who did or did not receive adjuvant treatment after the first operation. was 21 months in the former versus 10 months in the latter $(\mathrm{p}<0.001)$. Similar results were reported by Helseth et al. ${ }^{5}$, who analyzed a sample of 516 patients, with 56 subjected to reoperation; OS was longer in the latter compared to the ones who underwent primary surgery only, 18.4 months versus 8.6 months $(\mathrm{p}<0.001)$.

\section{Role of reoperation in survival after recurrence (SAR)}

Relative to the full study population, the median SARp in this study was 9.1 months. In the review Ryken et al. ${ }^{18}$ performed in 2014, the average SARp was nine months, which is much longer than the one reported in the review by Barbagallo et al. ${ }^{11}$ from 2008, which ranged from three to five months. Ringel et al. ${ }^{7}$ analyzed 503 patients who underwent reoperation for active disease and found that the SARp was 11.9 months, while in the study by Quick et al. ${ }^{19}$, in which patients with KPS score $>60$ and tumors likely to be entirely resected were subjected to repeated surgery, the SARp was 13 months.

\section{Relevance of adjuvant treatment}

In our study, performance of adjuvant treatment (RT and/or CT) before reoperation behaved as a prognostic factor for OS. Since 2009, all patients diagnosed with GBM at our institution have been indicated for adjuvant treatment based on the Stupp protocol' ${ }^{2}$. However, as a function of problems inherent to the Brazilian health system, the tumors recurred in $41 \%$ of the patients before the adjuvant treatment was initiated, a fact that was associated with reduced OS in that group compared to the cases in which the tumors recurred after adjuvant treatment (15.9 vs. 23.1 months; p: 0.008).

The impact of adjuvant treatment resulting in longer survival of patients with GBM has been previously reported in the literature ${ }^{5,15,20,21}$. Stark et al. ${ }^{21}$ assessed 492 patients with GBM and found that RT and CT alone or in combination had an impact on OS. The same conclusion was reached by Filippini et al. ${ }^{15}$ in their study of 676 patients with GBM.

\section{Extent of resection at reoperation}

Relative to survival after reoperation, the only independent factors on both univariate and multivariate analysis were the extent of resection at reoperation $(R R=0.3$; $95 \% \mathrm{CI}=0.1-0.7 ; \mathrm{p}=0.005)$ and performance of adjuvant treatment after reoperation $(\mathrm{RR}=0.4 ; 95 \% \mathrm{CI}=0.2-0.8$; $\mathrm{p}=0.016)$. Relative to the patients with TR at reoperation, the subsequent performance of adjuvant treatment did not exert any impact on SARp on multivariate analysis ( $p=0.089)$. However, adjuvant treatment exerted an impact on SARp in the cases with PR at reoperation $(p=0.044)$.

Yong et al. ${ }^{22}$ confirmed the relevance of the extent of resection at reoperation after finding that a residual tumor volume of less than $3 \mathrm{~cm}^{3}$ after reoperation exerted an impact on the patients' survival: OS values were 20 months in patients with TR, 11 months in patients with residual tumor volume less than $3 \mathrm{~cm}^{3}$ and five months when the residual 
Table 4. Univariate and multivariate analyses relative to overall survival.

\begin{tabular}{|c|c|c|c|c|c|c|c|}
\hline \multirow{2}{*}{ Variable (n) } & \multicolumn{3}{|c|}{ Univariate analysis } & \multirow{2}{*}{$\begin{array}{c}\text { Median OS } \\
\text { (Months) }\end{array}$} & \multicolumn{3}{|c|}{ Multivariate analysis } \\
\hline & $\mathrm{RR}$ & $95 \% \mathrm{Cl}$ & $\mathrm{p}$ value & & $\mathrm{RR}$ & $95 \% \mathrm{Cl}$ & $\mathrm{p}$ value \\
\hline \multicolumn{8}{|l|}{ Gender } \\
\hline Male (26) & 0.6 & $0.3-1.2$ & 0.159 & 17 & & & NS \\
\hline Female (13) & 1 & & -- & 26 & & & \\
\hline \multicolumn{8}{|l|}{ Age } \\
\hline$\geq 50$ years old $(18)$ & 1.5 & $0.7-3.1$ & 0.282 & 20.8 & & & NS \\
\hline$<50$ years old $(21)$ & 1 & & & 19.1 & & & \\
\hline \multicolumn{8}{|l|}{ KPS score } \\
\hline$\geq 70(30)$ & 1.3 & $0.5-3.3$ & 0.528 & 20.1 & & & NS \\
\hline$<70(9)$ & 1 & & & 19.8 & & & \\
\hline \multicolumn{8}{|l|}{ Laterality } \\
\hline Right (18) & 1.1 & $0.5-2.2$ & 0.862 & 20.1 & & & NS \\
\hline Lobe (21) & 1 & & & 19.8 & & & \\
\hline \multicolumn{8}{|c|}{ Frontal lobe localization } \\
\hline Yes (10) & 1 & $0.5-2.0$ & 0.929 & 20.8 & & & NS \\
\hline No (29) & 1 & & & 20.1 & & & \\
\hline \multicolumn{8}{|c|}{ Temporal lobe localization } \\
\hline Yes (11) & 1.3 & $0.6-2.6$ & 0.531 & 17 & & & NS \\
\hline No (28) & 1 & & & 21 & & & \\
\hline \multicolumn{8}{|l|}{$>1$ affected lobes } \\
\hline Yes (15) & 0.9 & $0.4-1.8$ & 0.68 & 19.1 & & & NS \\
\hline No (24) & 1 & & & 20.8 & & & \\
\hline \multicolumn{8}{|c|}{ Interval between operations } \\
\hline$\geq 6$ months (18) & 0.4 & $0.2-0.9$ & 0.023 & 23.6 & & & NS \\
\hline$<6$ months $(21)$ & 1 & & & 16.8 & & & \\
\hline \multicolumn{8}{|l|}{ RT delay } \\
\hline Yes (29) & 1.3 & $0.6-3.0$ & 0.467 & 20.1 & & & NS \\
\hline No (10) & 1 & & & 17 & & & \\
\hline \multicolumn{8}{|c|}{ First operation resection } \\
\hline $\operatorname{TR}(23)$ & 1.4 & $0.7-3.1$ & 0.369 & 19.8 & & & NS \\
\hline PR (16) & 1 & & & 20.8 & & & \\
\hline \multicolumn{8}{|l|}{ Reoperation resection } \\
\hline $\operatorname{TR}(21)$ & 1.7 & $0.8-3.6$ & 0.137 & 23.1 & & & NS \\
\hline PR (18) & 1 & & & 16.8 & & & \\
\hline \multicolumn{8}{|c|}{ Adjuvant therapy after first operation } \\
\hline Yes (23) & 0.4 & $0.2-0.8$ & 0.008 & 23.1 & 0.3 & $0.2-0.7$ & 0.005 \\
\hline No (16) & 1 & & & 15.9 & 1 & & \\
\hline \multicolumn{8}{|c|}{ Adjuvant therapy after reoperation } \\
\hline Yes (26) & 1 & $0.5-2.2$ & 0.903 & 23.1 & & & NS \\
\hline No (13) & 1 & & & 19.8 & & & \\
\hline \multicolumn{8}{|l|}{ Recurrence } \\
\hline Distant (5) & 2.4 & $0.7-8.1$ & 0.148 & 25.9 & & & NS \\
\hline Local (34) & 1 & & & 19.1 & & & \\
\hline
\end{tabular}

RR: relative risk; Cl: confidence interval; OS: Overall Survival; KPS: Karnofsky Performance Status; RT: radiotherapy; TR: total resection; PR: partial resection. 

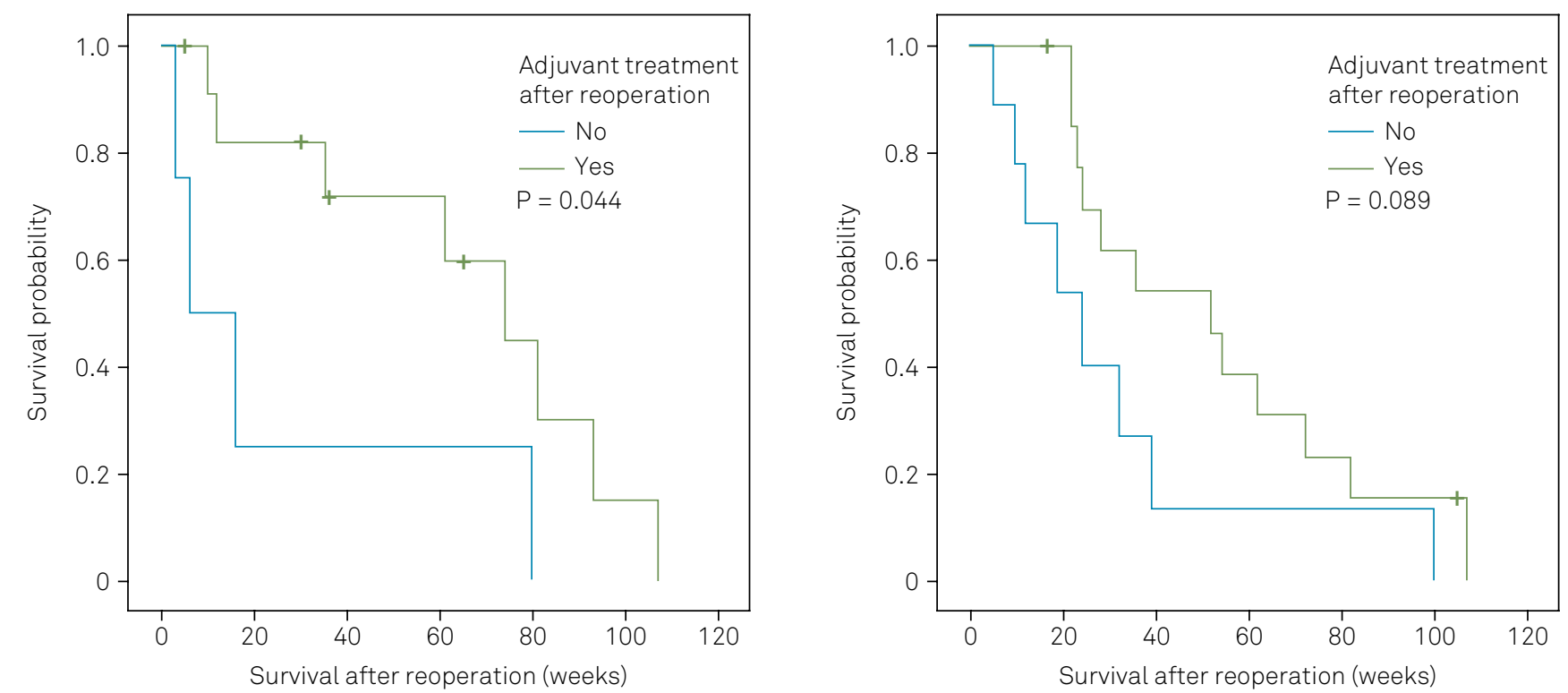

Figure 2. (A) Kaplan-Meier curve representing the Survival after reoperation (SARp) of patients subjected to parcial resection (PR) at reoperation and who did or did not receive adjuvant treatment after reoperation. (B) Kaplan-Meier curve representing the SARp of patients subjected to total Resection (TR) at reoperation and who did or did not receive adjuvant treatment after reoperation.

tumor volume was larger than $3 \mathrm{~cm}^{3}$. Following a study with 170 patients, Oppenlander et al..$^{23}$ concluded that an extent of resection larger than $80 \%$ in repeated surgery suffices to increase patients' survival.

\section{Influence of radiotherapy delay on survival}

To assess the influence of RT delay on survival, we compared the patients who had started RT within the first six weeks after surgery (no delay) to those who had started it more than six weeks afterwards (RT delay) and found no difference in their survival $(\mathrm{RR}=1.3 ; 95 \% \mathrm{CI}=0.6 ; \mathrm{p}=0.467)$. We chose that time interval because it was the one adopted in previous studies ${ }^{24,25}$. Our findings in this regard agree with data reported in the literature ${ }^{24,26}$. Although some authors found that RT delay has negative effects on $\mathrm{OS}^{25,27}$ this topic remains controversial. In turn, Loureiro et al. ${ }^{28}$ assessed the time elapsed from surgery to onset of RT at one public and one private healthcare service in Brazil and also failed to find any difference in $\mathrm{OS}$ in association with delayed $\mathrm{RT}(\mathrm{RR}=1.2$; $95 \% \mathrm{CI}=0.8-1.8 ; \mathrm{p}=0.470$ ).

Delay in the onset of RT is mainly due to the increase in the demand for this treatment modality as a function of population aging, with consequent elevations in the incidence rates of various types of cancer ${ }^{29}$. While difficulty in meeting the demand is encountered in developed countries, it is much more frequent in developing countries, especially in the public healthcare setting ${ }^{28}$. In Brazil, the situation is especially worrisome, as the increasing demand for RT created an inefficient system; thus, only $65.9 \%$ of the patients needing RT actually receive it, having to wait a median interval of almost four months, independent of the type of cancer ${ }^{28}$. Our service represents a classic example of these problems: onset of RT was delayed in $74 \%$ of the patients analyzed in the present study: the median interval from surgery to onset of RT was eight months. One of the patients in our sample had to wait 23 weeks (5.3 months) to start RT.

Nevertheless, upon analyzing the subgroup of patients with delayed RT, no difference was found in OS between the patients with tumor recurrence before/during RT and the ones in whom the tumor recurred after the end of RT $(\mathrm{RR}=2.0 ; 95 \% \mathrm{CI}=0.8-4.8 ; \mathrm{p}=0.11)$. Thus, we are also led to believe that the patients with tumor relapse before or during RT are candidates for reoperation. That is, reoperation of patients who relapsed before RT due to treatment delay afforded the opportunity to conduct adjuvant treatment.

\section{Study limitations}

Our study exhibits some limitations, including small sample size; retrospective data collection; lack of uniformity in the adjuvant treatment instituted after the first and second operations; selection bias, as only patients with KPS scores over 70 and lesions considered to be surgically accessible were subjected to reoperation; and the fact that we did not compare the patients subjected to re-resection to others who did not undergo a second surgery.

\section{Future perspectives}

Among the most promising treatments for GBM, targeted molecular therapies have been widely investigated in recent years. However, no effective results have yet been achieved. Intratumor heterogeneity and the heterogeneity between the primary and recurrent tumors represent significant limitations to the success of this type of therapeutic approach. Collecting samples of the relapsed tumor, 
whenever possible, is crucial to advance not only in the assessment of the response to targeted therapies but also in the understanding of the mechanisms of resistance to treatment $^{30}$. In this regard, reoperation, provided it is safe, will likely become an essential component of the management of these patients in the future.

In conclusion, despite the limitations of our study, we sought to describe the actual conditions of the treatment of recurrent glioblastoma at a Brazilian public healthcare service. In many developing countries, therapeutic alternatives and targeted therapies remain obscure but keeping in mind factors such as age, KPS prior to and after surgery, degree of resection TR vs. PR and adjuvant RT and CT can still provide results comparable to modern day series. In spite of the delays and difficulties that conspired against the achievement of the ideally complete treatment, the length of survival of patients who underwent reoperation was similar to those reported in the literature. Our results indicate that reoperation is feasible and may be considered a treatment option for a select group of patients with recurrent GBM in Brazil.

\section{Acknowledgements}

Fernando A. P. Ferraz (in memoriam), M.D., PhD, founder of the Neuro-oncology Group in Federal University Of São Paulo, and Luiz Daniel Cetl, M.D., for participation in the management care of some of these patients.

\section{References}

1. Egan KM, Thompson RC, Nabors LB, Olson JJ, Brat DJ, Larocca RV et al. Cancer susceptibility variants and the risk of adult glioma in a US case-control study. J Neuroncol. 2011;104(2):535-42. doi:10.1007/s11060-010-0506-0

2. Stupp R, Mason WP, Bent MJ, Weller M, Fisher B, Taphoorn MJ et al. Radiotherapy plus concomitant and adjuvant temozolomide for glioblastoma. New Engl J Med. 2005;352(10):987-96. doi:10.1056/NEJMoa043330

3. Darefsky AS, King JT, Jr., Dubrow R. Adult glioblastoma multiforme survival in the temozolomide era: a population-based analysis of surveillance, epidemiology, and end results registries. Cancer. 2012;118(8):2163-72. doi:10.1002/cncr.26494

4. Stupp R, Hegi ME, Mason WP, Bent MJ, Taphoorn MJ, Janzer RC et al. Effects of radiotherapy with concomitant and adjuvant temozolomide versus radiotherapy alone on survival in glioblastoma in a randomised phase III study: 5-year analysis of the EORTC-NCIC trial. Lancet. Oncology. 2009;10(5):459-66. doi:10.1016/S1470-2045(09)70025-7

5. Helseth R, Helseth E, Johannesen TB, Langberg CW, Lote K, Rønning P et al. Overall survival, prognostic factors, and repeated surgery in a consecutive series of 516 patients with glioblastoma multiforme. Acta Neurol Scand. 2010;122(3):159-67. doi:10.1111/j.1600-0404.2010.01350.x

6. Krex D, Klink B, Hartmann C, Deimling A, Pietsch T, Simon M et al. Long-term survival with glioblastoma multiforme. Brain. 2007;130(10):2596-606. doi:10.1093/brain/awm204

7. Ringel F, Pape H, M, Krex D, Bock HC, Misch M et al. Clinical benefit from resection of recurrent glioblastomas: results of a multicenter study including 503 patients with recurrent glioblastomas undergoing surgical resection. Neuro-oncol. 2016;18(1):96-104. doi:10.1093/neuonc/nov145

8. Lacroix M, Abi-Said D, Fourney DR, Gokaslan ZL, Shi W, DeMonte F et al. A multivariate analysis of 416 patients with glioblastoma multiforme: prognosis, extent of resection, and survival. J Neurosurg. 2001;95(2):190-8. doi:10.3171/jns.2001.95.2.0190

9. Samis Zella MA, Wallocha M, Slotty PJ, Isik G, Hänggi D, Schroeteler $J$ et al. Evaluation of post-operative complications associated with repeat resection and $\mathrm{BCNU}$ wafer implantation in recurrent glioblastoma. Acta Neurochir (Wien). 2014;156(2):313-23. doi:10.1007/s00701-013-1931-6

10. Hong B, Wiese B, Bremer M, Heissler HE, Heidenreich F, Krauss JK et al. Multiple microsurgical resections for repeated recurrence of glioblastoma multiforme. Am J Clin Oncol. 2013;36(3):261-8. doi:10.1097/COC.0b013e3182467bb1
11. Barbagallo GM, Jenkinson MD, Brodbelt AR. "Recurrent" glioblastoma multiforme, when should we reoperate? Br $\mathrm{J}$ Neurosurg. 2008;22(3):452-55. doi:10.1080/02688690802182256

12. Chaichana KL, Zadnik P, Weingart JD, Olivi A, Gallia GL, Blakeley $J$ et al. Multiple resections for patients with glioblastoma: prolonging survival.J Neurosurg. 2013;118(4):812-20. doi:10.3171/2012.9.JNS1277

13. Sughrue ME, Sheean T, Bonney PA, Maurer AJ, Teo C. Aggressive repeat surgery for focally recurrent primary glioblastoma: outcomes and theoretical framework. Neurosurg Focus. 2015;38(3):E11. doi:10.3171/2014.12.FOCUS14726

14. Clarke JL, Ennis MM, Yung WK, Chang SM, Wen PY, Cloughesy TF et al. Is surgery at progression a prognostic marker for improved 6 -month progression-free survival or overall survival for patients with recurrent glioblastoma? Neuro-oncol. 2011;13(10):1118-24. doi:10.1093/neuonc/nor110

15. Filippini G, Falcone C, Boiardi A, Broggi G, Bruzzone MG, Caldiroli $D$ et al. Prognostic factors for survival in 676 consecutive patients with newly diagnosed primary glioblastoma. Neuro-oncol. 2008;10(1):79-87. doi:10.1215/15228517-2007-038

16. Gorlia T, Stupp R, Brandes AA, Rampling RR, Fumoleau P, Dittrich C et al. New prognostic factors and calculators for outcome prediction in patients with recurrent glioblastoma: a pooled analysis of EORTC Brain Tumour Group phase I and II clinical trials. Eur J Cancer. 2012;48(8):1176-84. doi:10.1016/j.ejca.2012.02.004

17. McNamara MG, Lwin Z, Jiang H, Templeton AJ, Zadeh G, Bernstein M et al. Factors impacting survival following second surgery in patients with glioblastoma in the temozolomide treatment era, incorporating neutrophil/lymphocyte ratio and time to first progression. J Neurooncol. 2014;117(1):147-52. doi:10.1007/s11060-014-1366-9

18. Ryken TC, Kalkanis SN, Buatti JM, Olson JJ. The role of cytoreductive surgery in the management of progressive glioblastoma : a systematic review and evidence-based clinical practice guideline. J Neurooncol. 2014;118(3):479-88. doi:10.1007/s11060-013-1336-7

19. QuickJ, Gessler F, Dützmann S, Hattingen E, Harter PN, Weise $L M$ et al. Benefit of tumor resection for recurrent glioblastoma.J Neurooncol. 2014;117(2):365-72. doi:10.1007/s11060-014-1397-2

20. Stark AM, Nabavi A, Mehdorn HM, Blömer U. Glioblastoma multiforme-report of 267 cases treated at a single institution. Surg Neurol. 2005;63(2):162-69. doi:10.1016/j.surneu.2004.01.028

21. Stark AM, Bergh J, Hedderich J, Mehdorn HM, Nabavi A. Glioblastoma: clinical characteristics, prognostic factors and survival in 492 patients. Clin Neurol Neurosurg. 2012;114(7):840-5. doi:10.1016/j.clineuro.2012.01.026 
22. Yong RL, Wu T, Mihatov N, Shen MJ, Brown MA, Zaghloul KA et al. Residual tumor volume and patient survival following reoperation for recurrent glioblastoma. J Neurosurg. 2014;121(4):802-9. doi:10.3171/2014.6.JNS132038

23. Oppenlander ME, Wolf AB, Snyder LA, Bina R, Wilson JR, Coons SW et al. An extent of resection threshold for recurrent glioblastoma and its risk for neurological morbidity. J Neurosurg. 2014;120(4):846-53. doi:10.3171/2013.12.JNS13184

24. Blumenthal DT, Won M, Mehta MP, Curran WJ, Souhami L, Michalski $\mathrm{JM}$ et al. Short delay in initiation of radiotherapy may not affect outcome of patients with glioblastoma: a secondary analysis from the radiation therapy oncology group database. J Clin Oncol. 2009;27(5):733-9. doi:10.1200/JC0.2008.18.9035

25. Valduvieco I, Verger E, Bruna J, Caral L, Pujol T, Ribalta T et al. Impact of radiotherapy delay on survival in glioblastoma. Clin Transl Oncol. 2013;15(4):278-82. doi:10.1007/s12094-012-0916-x

26. Graus F, Bruna J, Pardo J, Escudero D, Vilas D, Barceló I et al. Patterns of care and outcome for patients with glioblastoma diagnosed during 2008-2010 in Spain. Neuro-oncol. 2013;15(6):797-805. doi:10.1093/neuonc/not013
27. Spratt DE, Folkert M, Zumsteg ZS, Chan TA, Beal K, Gutin $\mathrm{PH}$ et al. Temporal relationship of post-operative radiotherapy with temozolomide and oncologic outcome for glioblastoma.J Neurooncol. 2014;116(2):357-63. doi:10.1007/s11060-013-1302-4

28. Loureiro LV, Pontes LB, Callegaro-Filho D, Koch LO, Weltman E, Victor ES et al. Waiting time to radiotherapy as a prognostic factor for glioblastoma patients in a scenario of medical disparities. Arq Neuro-psiquiatr. 2015;73(2):104-10. doi:10.1590/0004-282X20140202

29. Chen Z, King W, Pearcey R, Kerba M, Mackillop WJ. The relationship between waiting time for radiotherapy and clinical outcomes: a systematic review of the literature. Radiother Oncol. 2008;87(1):3-16. doi:10.1016/j.radonc.2007.11.016

30. Prados MD, Byron SA, Tran NL, Phillips JJ, Molinaro AM, Ligon $\mathrm{KL}$ et al. Toward precision medicine in glioblastoma: the promise and the challenges. Neuro-oncology. 2015;17(8):1051-63. doi:10.1093/neuonc/nov031 